\title{
QUALITY IMPROVEMENT OF PRODUCT DATA EXCHANGED BETWEEN ENGINEERING AND PRODUCTION THROUGH THE INTEGRATION OF DEDICATED INFORMATION SYSTEMS
}

\author{
Anis BEN KHEDHER \\ DISP Laboratory, University of Lyon, Lumière \\ Lyon2, IUT Lumière \\ Lyon, France
}

\author{
Sébastien HENRY \\ DISP Laboratory, University of Lyon, Claude \\ Bernard Lyon1, IUT B \\ Lyon, France
}

\author{
Abdelaziz BOURAS \\ DISP Laboratory, University of \\ Lyon, Lumière Lyon2, \\ IUT Lumière \\ Lyon, France
}

\begin{abstract}
Today, within the global Product Lifecycle Management (PLM) approach, success of design, industrialization and production activities depends on the ability to improve interaction between information systems that handle such activities. Enterprises deploy mainly PLM system, Enterprise Resource Planning system (ERP) and Manufacturing Execution System (MES) in order to manage sufficient product-related information and provide better customer-products. This paper proposes a methodological approach to improve the quality of data exchanged between engineering and production. This involves the integration among information systems especially the PLM-MES integration. Thus, the proposed approach aims to overcome the problem of data heterogeneity by proposing a mediation system resolving syntactic and semantic conflicts of data managed by these systems.
\end{abstract}

Keyword words: data quality, PLM, MES, integration, mediation system, web service.

\section{INTRODUCTION}

In an extended enterprise context, customers are demanding more customization and responsiveness, Information Systems (IS) are proliferating at an increasing rate and the product life cycle is getting shorter. These factors imply permanent product data changes happen in the design phase and the industrialization phase. For the bulk of changes, some lead to redesign within the same product and others lead to new product versions creation. The data related to these changes should be transmitted quickly to production in order to ensure the product manufacturing using the right version information. This data exchange between engineering and production involves quality improvement of the exchanged data: interpretation, accessibility, completeness and freshness. These interactions between engineering and production are performed by the dedicated IS.

The ERP had emerged as the enterprise management system and as the heart of the enterprise information system [1]. This system focus mainly on managing customer orders processes by orchestrating all company's activities (commercial, financial, purchasing, logistics, production, etc.) [2]. However, over the last decade, the emergence of the PLM concept associated to the development of PLM support applications have generated multiple evolutions in the enterprises information systems. To meet the specific needs of each enterprise's activities, the integration of information systems required for these activities has been gradually realized. For instance, the development of information systems for controlling production (MES) [3] led to the standardization by the ISA 95 - IEC 62264 standard of MES functions and data structure exchanged between ERP and MES. This standard aims to enhance the integration of MES and ERP whose vendors are generally different [4]. As we mentioned earlier, at that time, the PLM system is not yet 
mature. Thus, the IEC 62264 was focused on a vertical collaboration from ERP to production. Based on this standard, the product-related data are needed for production management such as Bill Of Materials (BOM). For production planning and scheduling, product-related data are recorded in the ERP system. Moreover, the product-related data for production such as work instructions and for production operators are recorded in the MES. Nowadays, the deployment of PLM solutions challenges these choices and leads companies to redefine the borders of existing information systems (ERP and MES). However, the duration and deploying cost of these systems lead enterprises to limit changes to existing systems when deploying a PLM system. Thus, according to the enterprise strategy and the history of its information system (chronology of deployment of various information systems), the same information can be stored in more than one information systems. As revealed by the study "Integrating the PLM Ecosystem" conducted by Aberdeen Group in April 2008 [5] based on a survey of 260 companies, the "manufacturing processes" of a product is stored $15 \%$ in PLM, $36 \%$ in the ERP, $23 \%$ in the MES and finally even more surprising $26 \%$ in another system or not! These different solutions for productrelated data storage reveal the absence of serious data management and monitoring of processes that generate such data. Therefore, there is a challenge of absence of a continuous product-related data flow from design to production. This situation limits the visibility of product data over the production. This limitation is due to the delayed data update and to the communication of partial data to production. In order to tackle these challenges, it seems important to study the interaction between PLM and production management. The first part aims to clarify the issue addressed in this paper. The main characteristic of this issue is to address a problem of three nested information systems. In the next section, an analysis of different life cycles (product object, product instance, manufacturing system and purchase order) including the production stage, which is the intersection of these life cycles, lead to classify these life cycles processes into four categories. A comparison with the current coverage of processes by the existing IS (PLM, ERP and MES) leads firstly to confirm the current trend of PLM solutions evolution to the industrialization stage but also to define borders among these three systems. A study of interactions among the processes of various life cycles led to propose integration architecture of the three information systems. Following this analysis, the fourth part focuses on the integration between PLM and MES. Finally, we describe the proposed mediation system and web service architecture.

\section{INTERACTIONS AMONG LIFECYCLES}

Nowadays, the concept of digital manufacturing offers, from design to industrialization, several computer tools based on digital 3D models for simulation (simulation of machining, analysis of ergonomics, shop floor simulation, etc.) such as the solutions proposed by DELMIA and based on CATIA (Dassault
Systems). This tendency has already been started by some PLM vendors such as PTC that includes the MPM module (Manufacturing Process Management) to include, within the PLM solution, the industrialization stage [6]. Thus, the data handled by the PLM solution will be required for production management: Manufacturing Bill of Materials (MBOM) for Materials Requirements Planning (MRP) and manufacturing process, and other data required directly in the shop floor for the product manufacturing (MBOM, manufacturing process, programs of machines, work instructions and machine setup). Therefore, from the need for conventional integration of two information systems, PLM-ERP on one side and ERP-MES on another side, the problem that appears is the integration of these three IS. The integration of these three information systems is variable depending on the selected solutions and blurred because sometime one same data may be generated by two systems. Finally, this integration depends also on the product type that can be customized and manufactured to customer's request or, conversely, be manufactured from stock. Thus, this research work aimed to propose architecture for integrating these three systems. The first stage of this work consists on a life cycle analysis by focusing only on the exchanged data without taking into account the product and its impact on the frequency and timing of data exchanges. The second study based on a classification of products in five categories leads, firstly, to evaluate the frequency of data exchanges and thus classify the exchanges needed to be automated according to the product, and secondly to identify two data exchange scenarios The research on the interactions among PLM, production management and production is based on a detailed study of different life cycles. Thus, two different concepts of product are distinguished: product object and product instance. The product object is a virtual product or digital product, while the product instance is a physical product delivered to customer [7]. Therefore, we distinguished one life cycle related to each product type [8] [9]. Two other life cycles related to product manufacturing are studied: manufacturing system life cycle and purchase order life cycle.

\subsection{PRODUCT INSTANCE LIFECYCLE}

The product instance lifecycle consists of three stages: manufacturing, use and elimination. In the case of producing multiple product instances, the life cycles of different product instances are shifted in time: at the instant $\mathbf{t}$ when the instance $\mathbf{b}$ is manufactured, the instance $\mathbf{a}$ is used. Usually, the period of product use varies depending on product robustness, consumer behavior and use conditions.

\subsection{PRODUCT OBJECT LIFECYCLE}

The product object lifecycle consists of four stages: design, industrialization, marketing and withdrawal from market [9]. Product object design is performed by designers using several tools such as CAD tool (Computer Aided Design). The data and processes generated, during this stage, are increasingly supported by PLM solutions. At the end of this stage, several 
data and documents will be generated such as EBOM, CAD model and product configurations. The second stage of the object lifecycle is the industrialization. During this stage, manufacturing engineers perform the manufacturing process, the MBOM (Manufacturing BOM), work instructions for each operation and machine setup for each of the machine and shop floor programs for machines and robots, etc. The third stage is making the product on the market. The duration of this stage is the period where the product is offered in the catalog and the customer can buy it. The final stage is the withdrawal from the market. During this stage, it can be decided either to enhance the product to better meet market demands, or simply to abandon the product.

\subsection{MANUFACTURING SYSTEM LIFECYCLE}

We consider that a manufacturing system is itself a product that has the distinction of being manufactured in a single copy. For this product category, its life-cycle includes only four stages: design, manufacturing, use and elimination. At the stage of the product object industrialization whose instances are created by using the manufacturing system, the product manufacturing process and the manufacturing system architecture are extremely linked.

\subsection{PURCHASE ORDER LIFECYCLE}

Nowadays, companies are looking to minimize their inventories and to produce in approaching the concept of "Justin-time". In this context, customer orders management is an essential element for production. Therefore, taking into account the purchase order lifecycle is essential in the study of the production. It consists of four main stages: treatment, preparation, delivery and billing.

To synthesize, the analysis of previous lifecycles reveals that the production process is a meeting point of these lifecycles. The production can be defined as an instantiation of product object by using the manufacturing system in order to meet customer orders. Indeed, after the identification of the processes of each life cycle, a classification of these processes is carried out according to two criteria: process type and process output. Thus, we distinguished four categories of processes (Table 1).

TABLE 1. CLASSIFICATION OF PROCESSES

\begin{tabular}{|c|c|c|}
\hline & Certain & Uncertain \\
\hline Data & $\begin{array}{c}\text { Purchase order } \\
\text { (Treatment, Billing) }\end{array}$ & $\begin{array}{c}\text { Product object } \\
\text { (Design, Industrialization, Marketing, Withdrawal from market) } \\
\text { Manufacturing system } \\
\text { (Design) }\end{array}$ \\
\hline Physical effect & $\begin{array}{c}\text { Product instance } \\
\text { (Manufacturing) } \\
\text { Manufacturing system } \\
\text { (Use, Manufacturing) } \\
\text { Purchase order } \\
\text { (Preparation, Delivery) }\end{array}$ & $\begin{array}{c}\text { Product instance } \\
\text { (Use, Elimination ) } \\
\text { Manufacturing system } \\
\text { (Elimination) }\end{array}$ \\
\hline
\end{tabular}

The first criterion is the process type: certain or uncertain. A process is certain when its duration and output are known a priori. For instance, the production time of all operations are known a priori in case of absence of machines failures, lack of personnel, etc. In the case of an uncertain process, output and/or duration are not known a priori. This is particularly the case of design processes of product object whose result is never known and whose duration is very difficult to assess a priori. The product use process is also uncertain because it depends on user behavior.

The second criterion is the process output: data or physical effect. For example, the object design process generates only a virtual data. In the other hand, the manufacturing process generates physical products. From these two criteria, it is possible to define four categories of processes: Data-Certain, Data-Uncertain, Physical effect-Certain and Physical effectUncertain.

\subsection{PROCESSES COVERAGE PERFORMED BY IS}

After processes classification, we have identified the actual coverage of processes by current information systems (PLM, ERP and MES). In fact, the current processes coverage using the PLM, the ERP and the MES, is limited. The processes which are not covered by these systems are handled manually or using other systems. Consequently, PLM system suppliers tend to provide solutions that manage all processes and productrelated data at all life cycle stages. Because of the similarity of the nature of design and industrialization processes, there is a tendency today to manage these two stages by the PLM system. These solutions are based on the development of digital tools for design and are adequate to support the whole digital manufacturing using data generated during design and industrialization processes. For instance, the module MPMLink proposed by PTC can generate more industrialization data by focusing on the management of the industrialization process. This solution is available as a module added to the core of PLM solution WindChill [6]. However, in most current systems proposed on the market, a part of the industrialization process, the whole of marketing process and withdrawal from the market process are no longer managed by PLM systems. In order to address this gap between current and required coverage, we proposed a solution that allocates the data-certain processes to ERP system, data-uncertain processes to PLM system and physical effect-certain processes to the MES system (Fig. 1).

This definition of functional perimeters of different IS added to the identification of interactions among processes allow the identification of interactions among PLM, ERP and MES. The IS integrations study will be presented in the next section. 


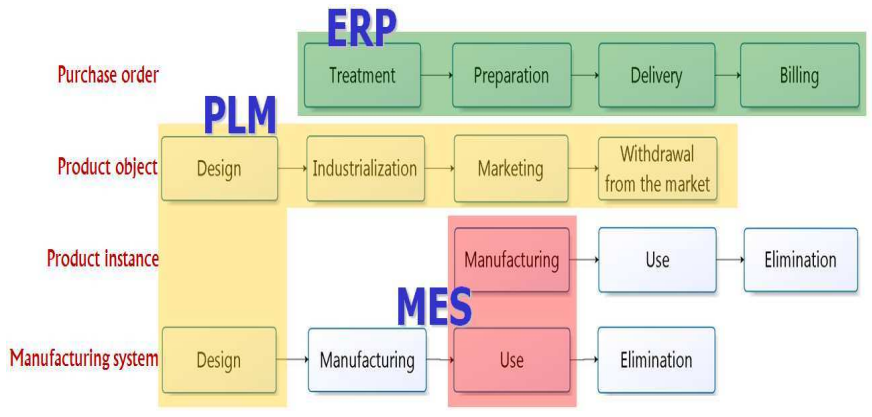

FIGURE 1. PROPOSED COVERAGE OF PROCESSES

\section{INFORMATION SYSTEMS INTEGRATIONS}

In modern manufacturing companies, PLM, ERP and MES are typically deployed to manage manufacturing operations. The integrations between these systems depend mainly on the manufacturing domain.

\subsection{ARCHITECTURE BASED ON ERP-MES INTEGRATION}

The architecture based on ERP-MES integration is a classic architecture deployed mainly in continuous/batch manufacturing. These manufacturing domains (food, pharmaceutical, chemical, etc.) are characterized by:

- The traceability constraint normalized by strict standards.

- A high automated system that facilitates data acquisition on the production system status.

- Simple implementation of performance analysis function.

- A single production system widely used to produce many products by changing the recipe. Thus, the emergence of a need to manage production changes and parameters transmission (quality, volume, etc.).

Thus, the deployment of MES in this manufacturing domain is essential. Such systems include the production tracking, performance analysis and production control systems for batch/continuous manufacturing.

The architecture based on ERP-MES integration use the specifications of IEC 62264 standards to exchange information between enterprise systems and control system without unnecessary time delays in order to optimize the production [10]. This standard provides the potential to simplify the deployment of ERP-MES integration. Data exchanged between ERP and MES can be structured in UML models. This work is the basis for the development of standard interfaces between ERP and MES [4]. For instance, Business to Manufacturing Markup Language (B2MML) is a set of XML schemas, corresponding to the IEC 62264 object models, intended to be used for data exchange between ERP and MES [10].

Part of the history of PLM systems strongly associated with CAD tools, these systems are still little used in this manufacturing domain where the products do not usually have geometric representations. However, the recipes complexity, its numbers and the high variants number lead PLM vendors to be interested to the continuous/batch manufacturing. This tendency is especially based on the deployment of change management processes.

On the basis of the discussion above, it can be concluded that the problem of ERP-MES architecture is the absence of product data management systems. In addition, in this architecture, the data quality is weak because several data (programs of machines, work instructions and machine setup) are transmitted manually to the shop floor using the MES.

\subsection{ARCHITECTURE BASED ON PLM-ERP INTEGRATION}

The architecture based on PLM-ERP integration is a classic architecture deployed mainly in discrete manufacturing (Automobile, Aerospace, Electronics, etc.) which are characterized by:

- The use of the PDM systems that naturally evolved to PLM systems.

- Significant evolution of PLM systems allowing mechanical assemblies of various parts modeled via CAD tools.

- Varies automation according to companies' capability (from not to fully automated).

- A problem of acquiring production system status information

- Little tracking constraints.

- The use of ERP systems including the production management module. This module is usually sufficient to control the production but without any real control of performed manufacturing operations.

In fact, several enterprises typically integrate PLM and ERP to ensure the consistency and use of product/shop floor related information throughout the enterprise and to use common product-related data and processes [11].

To synthesize, all these characteristics enable low penetration of MES systems in discrete manufacturing. However, multiple product versions, more flexible production systems and the need for realistic performance indicators lead to the development of MES for discrete manufacturing. In addition, the data quality in this architecture is weak because several data (programs of machines, work instructions and machine setup) are transmitted manually to the shop floor.

On the basis of the discussion above, it can be concluded that companies need to deploy PLM, ERP and MES in the same time. These deployments are usually successive over time and led to different changes. Therefore, the new architecture composed of PLM, ERP and MES leads companies to redefine boundaries of each system because the product-related information may need to flow across these boundaries several times. In fact, ERP system, as the only system communicating with MES, is unable to store and transmit all product-related data received from PLM for the MES. This inability is due to its 
data structure not expected to support detailed product data. Therefore PLM-MES integration becomes more and more required in these kinds of architectures. The general framework of data exchange among PLM, ERP and MES systems is shown in Fig. 2 [12].

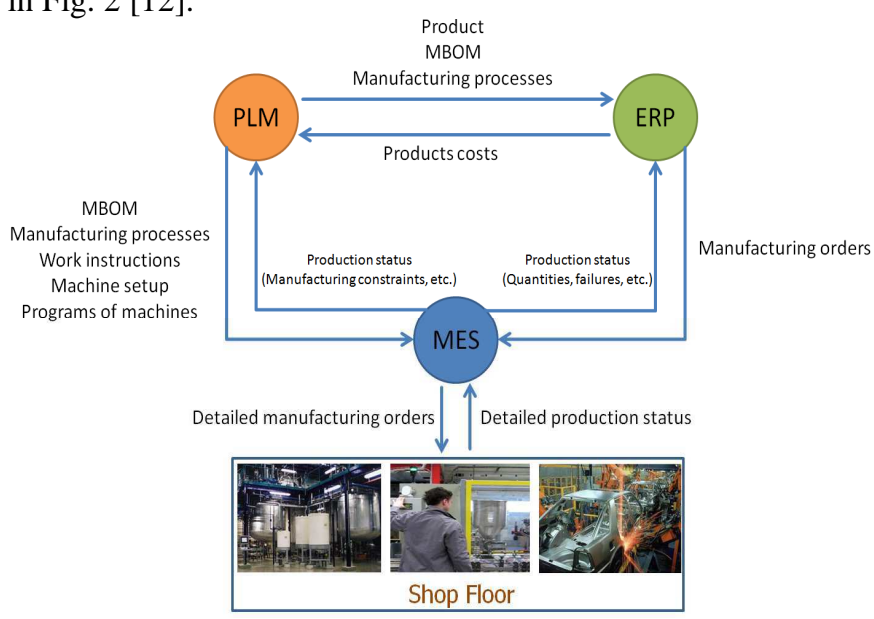

FIGURE 2. DATA EXCHANGE AMONG PLM, ERP AND MES

\subsection{PLM-MES INTEGRATION}

As we mentioned, this research work focuses mainly on PLM-MES integration. In this context, we identified the data to be exchanged between PLM and MES. By focusing on the product manufacturing, there are five data categories that have been identified [12]: MBOM, manufacturing process, work instructions, machine setup and programs of machines. These data have to be communicated to the MES from PLM. In another side, the MES should be able to communicate, to the PLM, production status (manufacturing constraints, etc.).

In our proposal, data related to the manufacturing system (machines, labor, materials, etc.) should be stored and managed into PLM system. In the other hand, the MES main role system transforms the digital product into a physical product. Nevertheless, it plays the opposite role of feed backing the production status information to PLM and ERP to enable the generation of performance indicators in order to improve future versions of the product information [13].

In fact, five interaction scenarios based on the product type have been proposed. The interaction frequency among PLM, ERP and MES varies depending on the degree of product customization. In fact, manufactured products can be classified into five major categories: contract product such as bridges, engineer-to-order such as aircraft and yachts, configure-to-order such as laptops, assemble-to-order such as cars and assembleto-stock such as cell phones. Due to the differences of the five interactions, we propose to define the characteristic of each one:

- Contract product: the production of this product leads to develop specific information system managing its development stages. However in the case of using PLM, ERP and MES, the interactions among these systems require multiple data exchanges between PLM and ERP in order to take into account each customer need within design works.

- Engineer-to-order: this is a high customized product. The production of this product is characterized by a high frequency of product data modification, a low volume of production and a high variance of product. The use of PLM system is very important in the design and industrialization stages; consequently, PLM-MES interaction is essential to ensure the passage of production information to MES.

- Configure-to-order: The interaction among PLM, ERP and MES in the case of producing this product led to use the ERP system to perform several calculations based on configuration rules defined within product design stage. Thus, the product customizing is realized only after product production.

- Assemble-to-order: the enterprise produces the same product for long periods of time. In that case, the frequency of product data modification is low. The interaction among PLM, ERP and MES is characterized by an important data exchange between ERP and MES enabling product production depending on the order to assemble.

- Assemble-to-stock: Same as assemble-to-order products, the frequency of product data modification is low.

\section{INTEGRATION SYSTEM}

\subsection{MAPPING OF ONTOLOGIES}

At this stage of our research, the main objective is to design a mediation system based on ontologies. This system tends to resolve syntactic and semantic data conflicts. To achieve this goal, we chose a multi-ontology approach for integration. In this approach, each information source has its own local ontology which can be enhanced from existing ontologies. The PLM ontology is inspired by the Core Product Model (CPM) [14] and TOrento Virtual Enterprise ontology model (TOVE) [15]. The MES ontology is inspired by the ADAptive holonic COntrol aRchitecture for distributed manufacturing systems model (ADACOR) [16] and The Almost Perfect Approach to Scheduling (TAPAS) [17]. Both ontologies (PLM and MES) are inter-linked using formalized mappings, defining corresponding elements of the source ontologies [18]. For this perspective, we have developed a mapping based on the combination of two methods of similarities calculation. The first method, called LESK method [19], is a method for calculating semantic similarities. In this method, the similarities calculation is done through consulting the WordNet [20] lexical dictionary. After sense disambiguation, WordNet provides synonyms of the 
compared elements. The similarity depends on the number of synonyms in common. Inspired by the method of calculating of Poulain [22], the calculation of semantic similarity based on the comparison of synonyms is:

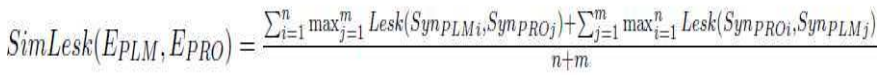

(Lesk (SynPLMi, SynPRoj) is the value of Lesk method for synonyms: SynPLMi and SynPRoj, $n$ and $\boldsymbol{m}$ correspond to the number of semantic terms associated to EPLM and EPRO.

The second method is based on the Edit Distance (also known as Levenshtein Distance [22]). We used the Levenshtein distance to calculate the syntactic similarity between two ontology elements:

$$
\operatorname{Leven}\left(T_{1}, T_{2}\right)=1-\frac{\text { DistLeven }\left(T_{1}, T_{2}\right)}{\text { nbmoy }}
$$

(Leven $(T 1, T 2)$ corresponds to the value of Levenshtein distance between T1 and T2, nbmoy is the average of number of characters of the two terms $\boldsymbol{T} \mathbf{1}$ and $\boldsymbol{T} 2$ ).

The calculation of final syntactic similarity is:

$\operatorname{SimLeven}\left(E_{P L M}, E_{P R O}\right)=\frac{\sum_{i=1}^{n} \max _{j=1}^{m} \operatorname{Leven}\left(T_{P L M}, T_{P R O}\right)+\sum_{j=1}^{m} \max _{i=1}^{n} \operatorname{Leven}\left(T_{P R O_{i}} T_{P L M}\right)}{n+m}$

(Leven (TPLMi, TPROj) corresponds to the similarity value for the terms: TPLMi and TPROj calculated using the above formula, $\boldsymbol{n}$ and $\boldsymbol{m}$ respectively correspond to the number of syntactic terms associated with EPLM and EPRO).

The combination of both methods allow us to calculate the similarities among ontological elements even if an element is not identified in Wordnet. After the identification of ontological similarities between two elements, data integration will be realised through matching data sources with the target data (Figure 3).

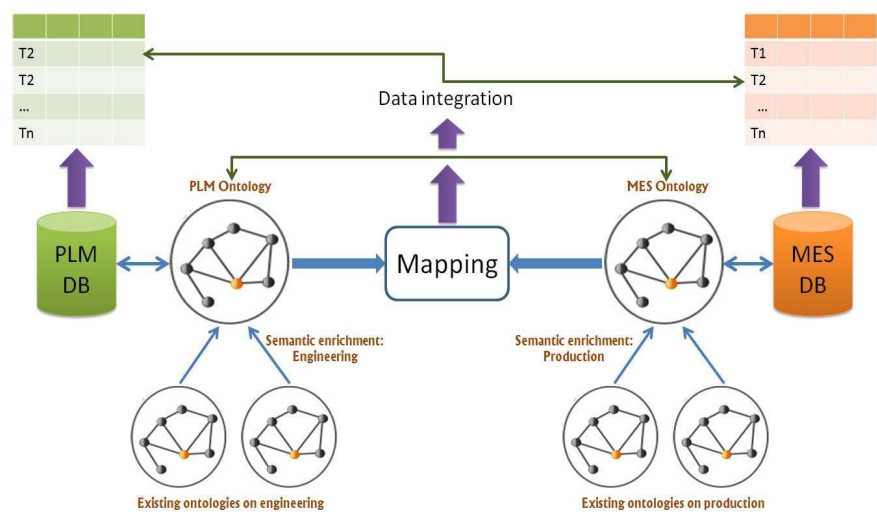

FIGURE 3. DEVELOPED MEDIATION SYSTEM

\subsection{WEB SERVICES USE}

The proposed architecture uses data exchange based on Internet technologies to help companies, especially expanded companies which manage a multi-site production, to take advantage of opportunities generated by the Web Services. The concept of "web service" means an application which is designed to support interoperable machine-to-machine interactions over a network, according to the definition of $\mathrm{W} 3 \mathrm{C}$. A web service is available on Internet by a service provider and accessible by clients through standard Internet protocols [23] [24]. Web services are independent from programming languages, object model as well as platforms for implementation [25] [26].

In the developed PLM-MES integration platform, the data exchange is realized using web services using XML files. Finally, we developed a web service for each data exchanged between PLM and MES: MBOM, manufacturing process, work instruction, machine setup and programs of machines.

\section{CONCLUSION}

The need for a more effective solution supporting interactions among design, industrialization and production teams is clearly stated by academics and practitioners worldwide. This interaction involves the data exchange among several information systems mainly used by a huge number of enterprises all over the world, i.e. PLM, ERP and MES. In this paper, by analyzing the problem mainly on the data exchange between the PLM and MES systems, the technological and nontechnological difficulties in the exchange, we suggested an ideal distribution of role of each system (PLM, ERP, and MES) and some data exchange models based on a life cycle analysis and depending on product type. These models enable also the PLMMES integration. This integration is important to manage data consistency and to avoid passing data in paper format which generate a lot of typing errors [27]. It shows some possibility for enterprises to realize the information integration of the PLM and MES systems to support the collaborative product development.

\section{REFERENCES}

[1] C. Cimalore, "PLM's changing role. Tooling \& Production", 73(4), 32, 2007.

[2] J. Shaohong and M. Qingjin, "Research on MES Architecture and Application for Cement Enterprises", IEEE International Conference on Control and Automation ThB5- 5, Guangzhou, CHINA - May 30 to June 1, 2007.

[3] MESA, "MES Explained: A High Level Vision", MESA International White Paper Number 6, September, 1997.

[4] ISA-S95, Enterprise Control System Integration, http, //www.isa-95.com/, 2000.

[5] D. Houlihan, "Integrating the PLM Ecosystem", Benchmark Report, Aberdeen Group, http://www.aberdeen.com/summary/report/benchmark/4646 -RA-integrating-plm-ecosystem.asp, 2008. 
[6] PTC, Manufacturing Process Management, Topic Sheet, 2074-MPM-TS-0107, 2007.

[7] S. Rachuri, E. Subrahmanian, A. Bouras, S. J. Fenves, S. Foufou and R. D. Sriram, "Information sharing and exchange in the context of product lifecycle management: Role of standards", Computer-Aided Design 40, pp: 789 800, 2008.

[8] A. Muhammad, S. Esque, L. Aha, J. Mattila, M. Siuko, M. Vilenius, J. Järvenpää, M. Irving, C. Damiani and L. Semeraro, "Combined application of Product Lifecycle and Software Configuration Management systems for ITER remote handling", Fusion Engineering and Design, 2009.

[9] J. Pereda, M. Hincapié and A. Molina, "Product, Process and Manufacturing System Lifecycles Analysis for a Concurrent Development", PLM'08 international conference, 2008.

[10] H. Schumacher and C. Johnsson, "Communication through B2MML - is that possible", The World Batch Forum North American Conference Chicago, IL May 1619, 2004.

[11] CIMdata, "PLM and ERP Integration: Business Efficiency and Value", A CIMdata Report, May 2010.

[12] A. Ben Khedher, S. Henry and A. Bouras, "Industrialization and manufacturing steps within the Global Product Lifecycle context”, APMS international conference, 2009

[13] M. Grieves, "Multiplying MES Value with PLM Integration", Whitepaper, 2007.

[14] S. J. Fenves, S. Foufou, C. E. Bock, N. Bouillon and R. D. Sriram, "Cpm 2 : A revised core product model for representing design information". Internal report nistir no. 7185, National Institute of Standards and Technology (NIST), 2004.

[15] J. Lin, M. S. Fox, and T. Bilgic, "A requirement ontology for engineering design", Concurrent Engineering: Research and Applications, 4(4):279-291, 1996.

[16] S. Borgo and P. Leitão, "Foundations for core ontology of manufacturing". IntegratedSeries in Information Systems, 14(1):751-775, 2007.

[17] P. Moutarlier, L. Geneste and B. Grabot, "Tapas: a modular framework to support reuse in scheduling software development". Production Planning and Control, 11(7):648-659, 2000.

[18] H. Wache, T. Vögele, U. Visser, H. Stuckenschmidt, G. Schuster , H. Neumann, and S. Hübner, "Ontology-Based Integration of Information - A Survey of Existing Approaches". In Stuckenschmidt, H., editor, IJCAI-2001 Workshop on Ontologies and Information Sharing, 2001.

[19] M. Lesk, "Automated sense disambiguation: How to tell pine cone from an ice cream cone. In 5th international conference on Systems documentation (SIGDOC)", page 2426, New York, USA, 1986.
[20] Fellbaum, C.: "WordNet: an Electronic Lexical Database", Computational Linguistics, 25, 2 (1998), 292296.

[21] T. Poulain, "Une approche orientée sémantique pour l'interrogation dune coopération de systèmes d'information basée sur des ontologies", Phd thesis, University of Bourgogne, 2009.

[22] V-I. Levenshtein, "Binary codes capable of correcting spurious insertions and deletions of ones. Problems of information transmission". Excellence project KnowledgeWeb, D2.2.3, (1): 817, 1965.

[23] D. Fensel, C. Bussler, and A. Maedche, "Semantic Web Enabled Web Services". In International Semantic Web Conference, Sardinia, Italy, pages 1, 2002.

[24] A. Ćatić, D. Bergsjö and J. Malmqvist, "Supporting Engineering Change Management by Integrating KBE and PLM in a Service Oriented Architecture", PLM08 international conference, 2008.

[25] P. Kellert and F. Toumani, "Les web services sémantiques", revue i3 hors série 2004 web sémantique, http://www.revue-3.org/hors_serie/ annee 2004 /index. php.

[26] S. Izza, L. Vincent and P. Burlat, "Ontology-Based Approach for Application Integration", Doctoral Symposium, Pre-proceedings of the, First International Conference on Interoperability of Enterprise Software and Applications: INTEROP-ESA'2005, Geneva, Switzerland, 2005.

[27] A. Ben Khedher, S. Henry and A. Bouras, "An analysis of the interaction among design, industrialization and production", PLM10 international conference, 2010. 